\title{
An Optimal Method for Lubricating Oil Compounds Properties Estimation - the Computer - Based Approach
}

\begin{abstract}
GABRIEL RADULESCU1*, DIANA CURSARU²
Petroleum -Gas University of Ploiesti, Control Engineering, Computers and Electronics Department, 39 Bucuresti Blvd., 100680, Ploiesti, Romania

Petroleum -Gas University of Ploiesti, Petroleum Processing Engineering and Environmental Protection Department, 39 Bucuresti Blvd., 100680, Ploiesti, Romania

Obtaining the commercial lubricating oils through an industrial method is a process which has an extensive complexity, requiring a very special attention paid to the final products quality. In this field, any new mixing compound, any new additive and any process improvement is more than welcome. Using the so called optimal mixing recipes - in order to get commercial lubricating oils by the base oils and corresponding additives - is a common way to lower the production cost and increase its quality. This paper proposes an original software tool, developed by the authors, which offers these recipes based on the final mixture properties (explicitly given). The application is built-up around the nonlinear programming and runs under $M A T L A B \circledast$ environment. It is a remarkably robust application, with good functionality and accuracy. Its performance is proved both in theory and practice, after laboratory experimental tests.
\end{abstract}

Keywords: lubricating oils, mixing recipes, nonlinear programming algorithm.

The lubricating oils production, in connection with their continuously improved quality, makes a remarkable progress in the industrial production, agriculture, transports and other fields of activity, being also correlated with primary resources preservation and energy saving necessity. By taking into account the quality specifications and the inherent process complexity, advanced technologies are used in industrial plants producing high quality lubricating oils.

The lubricating oils are fabricated by a mixture recipe of base oils and additives. On their turn, the required base oils are obtained from selected crude oils through methods as vacuum distillation, hydro-cracking, catalytic or solventbased de-waxing, solvent extraction and hydrogen or chemicals special treatments [ $1-5]$.

From the plantwide point of view, this process of obtaining commercial lubricating oils usually needs a permanent improvement, from small changes in a particular place to radical plant transformation. This paper deals with getting a minimal production cost for a commercial lubricating oil volumetric unity, which is a compulsory optimization for obtaining the base oils mixtures with their imposed properties. The authors present the mathematical model of the problem which imposes the subsequent software application structure. After the model's practical validation in laboratory, some final results are also presented as optimal mixing recipes.

\section{Characterizing the lubricating oils through a mathematical model}

The mostimportant function of lubricating oils is to treat the moving surfaces in order to lower the rub effects, among other general tasks that they must accomplish. In their turn, these tasks depend on the oil's physical and chemical properties: viscosity, viscosity index, pour point, flash point, density, acidity, refractive index, oxidation durability, ash content, color, Conradson Carbon Residue, Watson Characterization Factor [6 - 8].

Generally, the base oils are characterized by only three properties (viscosity, pour point, flash point) because among the 23 analytical oil properties, only these are mutually independent.

Taking into account that the lubricating oils may be obtained by mixing base oils, it is necessary to formulate appropriate additivity equations for each characteristic in order to be able to estimate the mixture's correspondent characteristic.

The lubricating oils are considered as liquid hydrocarbon mixtures, having an ideal behavior. Related to their physical properties, in general we may calculate them by using linear additivity equations. But there are other important situations when the characteristics are non-additive (in correlation with the components' volumetric fractions for instance). One good example are the properties chosen in this work to characterize a base oil -viscosity, pour point, flash point. Here is why the quoted literature recommends the use of the so-called transforming equations $[2,8]$.

If the $P$ is the property of the $i$ component and $X$ is its volumetric fraction in the mixture, an additive property satisfies the linear equation

$$
P_{\operatorname{mix}}=\sum_{i=1}^{n x} P_{i} \times X_{i}
$$

where $n c$ is the total number of components in the mixture and $P_{\text {mix }}$ is the corresponding mixture property.

$$
\text { If } P_{\operatorname{mix}} \neq \sum_{i=1}^{n} P_{i} \times X_{i} \text { the property is non additive. In order to }
$$

keep a linear form of the mixing equation, the $P$ property has to be replaced bya transformed variable called mixing index, $\mathrm{Ml}=\mathrm{f}(\mathrm{P})$ satisfying the linear equation

$$
M I=\sum_{i=1}^{n} M I_{i} \times X_{i},
$$

where $M I$ is the mixing index for the $i$ component and $M I$ is the mixing index for the mixture $[9,10]$.

The transforming equations permit the mixture properties estimation in correlation with the components' properties. For viscosity, pour point, flash point, the equations are as follows:

For viscosity $(v)$ :

\footnotetext{
* email: gabriel.radulescu@upg-ploiesti.ro
} 


$$
\begin{gathered}
M I_{-} v_{i}=33.46345 \times \log \log \left(v_{i}+0.8\right)+23.10219 ; \\
M I_{-} v_{\text {mix }}=\sum_{i=1}^{n x}\left(M I_{-} v_{i} \times X_{i}\right) \\
v_{\text {mix }}=10 \exp 10 \exp \left(\frac{M I_{-} v_{\text {mix }}-23.10219}{33.46345}\right)-0.8,
\end{gathered}
$$

where: $M I v_{i}$ is the mixing index for the $i$ component viscosity;

MI $v_{\text {mix }}$ - the mixing index for the mixture viscosity;

$v_{i}$ - the viscosity of the $i$ component [cSt];

$v_{\text {mix }}$ - the mixture viscosity [cSt].

For flash point $(T)$ :

$$
\begin{aligned}
& M I_{-} T_{i}=10^{\frac{-T_{i}}{586}} ; \\
& M I_{-} T_{m i x}=\sum_{i=1}^{n c}\left(M I_{-} T_{i} \times X_{i}\right) ; \\
& T_{m i x}=-58.6 \times \log \left(M I_{-} T_{m i x}\right),
\end{aligned}
$$

where: $M I-T_{i}$ is the mixing index for the $i$ component flash point;

MI $T_{\text {mix }}$ - the mixing index for the mixture flash point; $T_{i}$ - thixe flash point, $\left[{ }^{\circ} \mathrm{C}\right]$;

$T_{\text {mix }}$ - the mixture flash point, $\left[{ }^{\circ} \mathrm{C}\right]$.

For pour point (Pp):

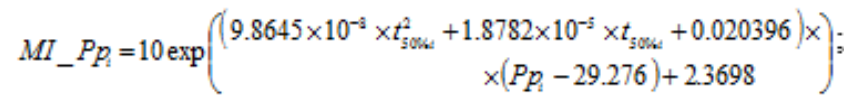

$$
\begin{aligned}
& M I_{-} P P_{\operatorname{mix}}=\sum_{i=1}^{n \varepsilon}\left(M I_{-} P P_{i} \times X_{i}\right) \\
& P p_{\text {max }}=\frac{\log \left(M I_{-} P p_{\text {mis }}\right)-2.3698}{9.8645 \times 10^{-3} \times t_{\text {soks }}^{2}+1.8782 \times 10^{-5} \times t_{\text {sold }}+0.020396}+29.276 \text {, }
\end{aligned}
$$

where: $M I_{-} P p_{i}$ is the mixing index for the $i$ component pourpoint;

$M I P p_{\text {mix }}$-the mixing index for the mixture pour point;

$t_{50 \%}$ - the temperature on the $i$ component TBP curve corresponding on $50 \%$ distilled;

$\mathrm{Pp}_{\mathrm{i}}$-the pour point of the $i$ component, $\left[{ }^{\circ} \mathrm{C}\right]$;

$P p_{\text {mix }}$-the pour point of the mixture, $\left[{ }^{\circ} \mathrm{C}\right]$.

The equations above had to be validated by laboratory tests. Three base oils having different flash points were used (so-called the light, medium and heavy oil), their characteristics being also determined by experiments. As it will be seen in the following part of the paper, different mixtures were obtained by using various volumetric fractions of each component. Consequently, for each resulting mixture, the viscosity, flash point and pour point were determined by laboratory experiments. The results that will be presented prove the validity and accuracy of the equations from (3) to (11) [2].

We know now that it is possible to estimate the physical properties of a coherent oil mixture when giving the volumetric fractions of each compound component. Accordingly, that means a particular lubricating oil, having imposed properties, may be obtained by mixing the basic components. In fact, this is the principle of the industrial method.

On the other hand, there are many possible (different) fractions of the base oils to be used leading to the same imposed properties for the resulting mixture. This has been demonstrated by the theory, being confirmed in practice. This is why an optimal criterion has to be identified, in order to increase the method efficiency when this criterion is satisfied [11].

This paper introduces an original computer-aided method for obtaining a mixture of base lubricating oils with given physical properties, following an optimal criterion to be fulfilled. The authors propose to minimize the mixture objective cost, this is why the objective function that should be minimized may be written as:

$$
f_{o b j}\left(X_{1}, X_{2}, \ldots, X_{n c}\right)=\sum_{i=1}^{n c}\left(p_{i} \cdot X_{i}\right),
$$

where $p$ are the components' unitary prices [8].

The software application developed by the authors is written in MATLAB $®$ (The MathWorks, Inc., 2018). It is described by a functional diagram as shown in figure 1, which indicates three programs modules [12].

OPT.M is the main application module, formulating the optimal problem. It uses the fmincon MATLAB ${ }^{\circledR}$ optimizing routine, which finds the minimum of a constrained nonlinear multivariable function, min $f(x)$, having linear and nonlinear constraints. These constraints may be written as equalities and inequalities. The software module is described by a standard nonlinear programming problem; this is why it usually does not need any user intervention. However, if the algorithm systematically fails to provide results which have a good physical sense, it is possible to modify the base lubricating oils' volumetric fractions (seen as initial optimal point estimation) [8].

The fmincon algorithm needs the other two application modules. First, the objective function is implemented in the OBJF.M file, according to the equation (12). In this module the user is able to change the objective function parameters or even the objective function itself. Usually, here we adjust the base lubricating oil unitary prices [8].

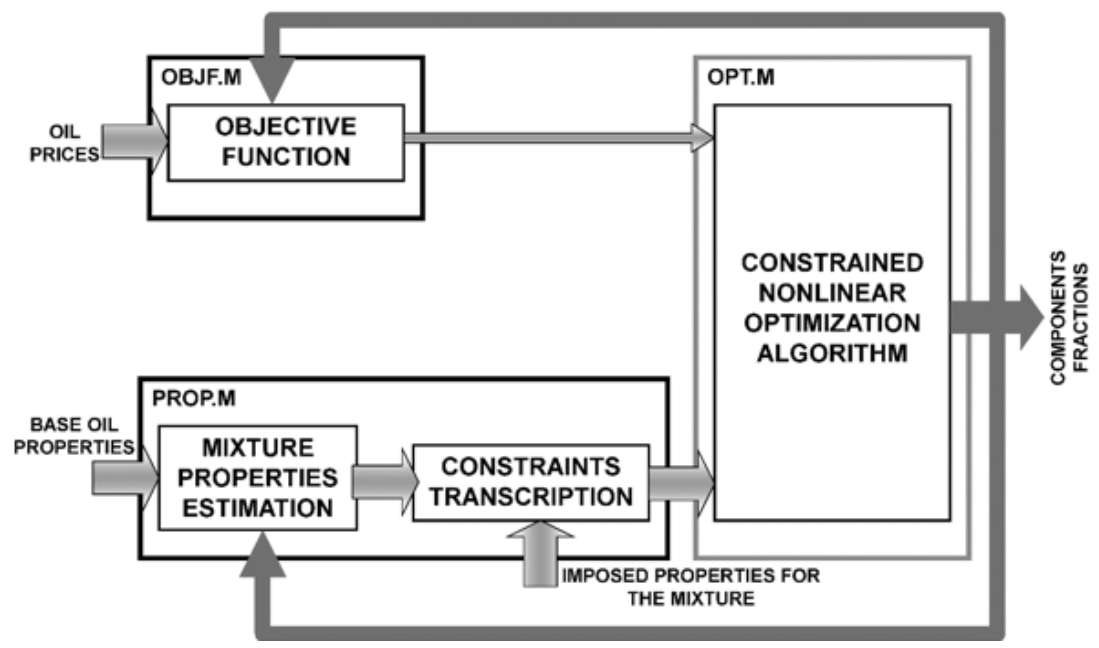

Fig. 1. The optimization software structure diagram 
The algorithm requires the description of the constraints, which is implemented in the last application module, PROP.M. The physical properties of the base lubricating oils (flash points, pour points, viscosities and TBP curves) and the imposed physical properties of the resulting mixture are the main inputs. To be more precise, we need the upper and lower accepted limits for these characteristics. Basically, this module uses the equations from (3) to (11) to estimate the mixture properties and then transcribes these constraints in a standard form accepted by the fmincon routine (having given their limits).

PROP.M is also at users' disposal, its initialization being critical when a particular application should be solved (as we have to take into account the basic components and resulting mixture properties) [8].

To sum things up, the basic guidelines when running the optimization software consist in accurately giving the base oils' properties, formulating the constraints in a pertinent form and conferring the significance of the initial point for the algorithm [13, 14].

\section{The experimental part: obtaining the lubricating oil mixtures using the authors' software approach}

The authors present, as an application overview, the example of obtaining a mixture with given properties by determining the optimal volumetric fractions of three base lubricating oils. These components may be characterized by the data from the table 1 .

As seen from table's last column, we followed the standard experimental procedures when determining the oil's properties (ASTM D-445, ASTM D-2270, ASTM D-97, ASTM D-92, ASTM D-86 and ASTM D-1747).

As previously known, the viscosity index of lubricating oils is actually a measure of the behavior of the kinematic viscosity while changing temperature between 40 and $100^{\circ} \mathrm{C}$. It is a unitless number and is calculated from their kinematic viscosities at 40 and $100^{\circ} \mathrm{C}$. At $40^{\circ} \mathrm{C}$, the oils were introduced in a Ubbelohde capillary (until the gauge line) that has a specific capillarity and a thermometer is also set in the larger side of the capillary. The whole was putin a water bath of fixed $40^{\circ} \mathrm{C}$ and then the oil temperature (into the viscometer) started to rise until it reaches that of the bath. When itis $40^{\circ} \mathrm{C}$, the procedure was ready to apply.

The kinematic viscosity was measured by recording the time sample needs to cross an orifice of a capillary under the force of gravity. This orifice created a fixed friction resisting the oil flow. Once the temperature was $40^{\circ} \mathrm{C}$, a vacuum hose was linked to the Ubbelhode capillary to let the oil rise up. It must fill the orifice when vacuum hose disconnected (due to the force of gravity). The time started when oil's level was at the first orifice top line and ended when it was at the second bottom line. This procedure was repeated three times, and the average was the most accurate data to be registered.

At $100^{\circ} \mathrm{C}$, the same procedure and the same concept was repeated but in a bath of glycerin (never water). Once the time was measured, the kinematic viscosity was directly calculated by multiplying the capillary constant and that time.

Regarding the pour point, it is in fact the lowest temperature at which the oil is still flowing. This property helps to know what will be the behavior of the oil in some cold regions or under severe cold weather conditions. The equipment required for the test was a cylindrical tube (the test jar) with a cork that holds a thermometer to measure the fluid temperature continuously, and a cooling medium (an electric machine with a cold basin that provides a constant rate of cooling).

The procedure consisted in filling with oil the test jar until the mark level, covering it with the cork carrying the thermometer. The test jar was put in the basin and the cooling process was started. When there was no expectation about the pour point, we checked the specimen every decrease of $3^{\circ} \mathrm{C}$ by removing the test jar from the basin and incline it for 5 seconds to notice if the fluid was still flowing or it solidified. When any idea about the pour point temperature existed, the flow check was started just 10 degrees before the expected value in a same way. When the oil was not flowing for more than five seconds, the test ended and the pour point was determined by adding three degrees to the temperature at which the oil solidified.

Finally, the procedure used for determining the flash point of oils was the open cup one. The oil was put in an open cup which was heated and, at intervals, a flame was brought over the surface. The flash point of the oils was the temperature to which the heated oil produced an ignitable vapor-air mixture above the liquid when exposed to this open flame.

In order to test the relevance of the equations from (3) to (11), different volumetric fractions of base lubricating oils were mixed and a comparison between the experimental results and the results given by the PROP.M module was done. The authors handled laboratory tests for determining the mixture viscosity, flash point and pour point. As shown in the tables 2, 3 and 4, there is an excellent accord between the properties' estimation by the software application and the experiments based on ASTM D-445, ASTM D-2270, ASTM D-97, ASTM D-92, ASTM D-86 and ASTM D-1747 procedures.

The above results prove that PROP.M module gives valuable information in this case and it is appropriate to be used in the optimization problem.

To fully test the entire application, the authors imposed different properties for the resulting mixture. The nonlinear

Table 1

BASE OILS CHARACTERISTICS

\begin{tabular}{|l|c|c|c|l|}
\hline \multicolumn{1}{|c|}{ Characteristics } & Light oil (LO) & $\begin{array}{c}\text { Medium oil } \\
(\mathrm{MO})\end{array}$ & Heavy oil (HO) & Analyzing methods \\
\hline Viscosity at $40^{\circ} \mathrm{C}[\mathrm{cSt}]$ & 25.57 & 34.27 & 125.48 & ASTM D-445 \\
\hline Viscosity at $100^{\circ} \mathrm{C}[\mathrm{cSt}]$ & 4.88 & 5.6 & 12.7 & ASTM D-445 \\
\hline Viscosity index & 114 & 101 & 92 & ASTM D-2270 \\
\hline Pour point $\left[{ }^{\circ} \mathrm{C}\right]$ & -9 & -4 & -6 & ASTM D-97 \\
\hline Flash point $\left[{ }^{\circ} \mathrm{C}\right]$ & 214 & 224 & 241 & ASTM D-92 \\
\hline t50\% $\left[{ }^{\circ} \mathrm{C}\right]$ & 445 & 480 & 530 & ASTM D-86 \\
\hline Refractive index & 1.1485 & 1.4865 & 1.4909 & ASTM D-1747 \\
\hline Unitary prices [\$/barrel] & 230 & 240 & 250 & - \\
\hline
\end{tabular}




\begin{tabular}{|c|c|c|c|}
\hline $\begin{array}{c}\text { Mixture } \\
\text { \%LO+\%MO+\%HO }\end{array}$ & MI_v mix $_{\text {mox }}$ & $\begin{array}{c}\text { Experimental } \\
\text { viscosity [cSt] }\end{array}$ & $\begin{array}{c}\text { Calculated } \\
\text { viscosity [cSt] }\end{array}$ \\
\hline $10+30+60$ & 31.98 & 66.70 & 68.80 \\
\hline $20+20+60$ & 31.86 & 65.20 & 66.40 \\
\hline $30+20+50$ & 31.29 & 53.93 & 56.40 \\
\hline $50+30+20$ & 29.70 & 35.80 & 36.80 \\
\hline $30+50+20$ & 29.95 & 39.00 & 39.30 \\
\hline $80+10+10$ & 28.89 & 28.80 & 30.10 \\
\hline $20+60+20$ & 30.07 & 39.00 & 40.50 \\
\hline
\end{tabular}

Table 2

MIXTURE CHARACTERISTICS

(VISCOSITY)

\begin{tabular}{|c|c|c|c|c|}
\hline $\begin{array}{c}\text { Mixture } \\
\text { \%LO+\%MO+\%HO }\end{array}$ & $\begin{array}{c}\mathbf{t}_{50 \%} \\
{\left[{ }^{0} \mathrm{C}\right]}\end{array}$ & $\begin{array}{c}\text { Experimental } \\
\text { pour point, } \\
{\left[{ }^{0} \mathrm{C}\right]}\end{array}$ & $\begin{array}{c}\text { Calculated pour } \\
\left.\text { point, [ }{ }^{\circ} \mathrm{C}\right]\end{array}$ \\
\hline $10+30+60$ & 506 & 2.879 & -5.0 & -5.6 \\
\hline $20+20+60$ & 503 & 2.774 & -6.0 & -6.0 \\
\hline $30+20+50$ & 494 & 2.892 & -6.0 & -6.3 \\
\hline $50+30+20$ & 472 & 3.348 & -7.0 & -6.6 \\
\hline $30+50+20$ & 479 & 3.557 & -5.0 & -5.6 \\
\hline $80+10+10$ & 457 & 3.256 & -10.0 & -8.0 \\
\hline $20+60+20$ & 483 & 3.661 & -5.0 & -5.2 \\
\hline
\end{tabular}

Table 3

MIXTURE CHARACTERISTICS (POUR POINT)

\begin{tabular}{|c|c|c|c|}
\hline $\begin{array}{c}\text { Mixture } \\
\% \mathbf{L O}+\% \mathbf{M O}+\% \mathrm{HO}\end{array}$ & MI_T $_{\text {mix }}$ & $\begin{array}{c}\text { Experimental } \\
\text { flash point }\left[{ }^{\circ} \mathbf{C}\right]\end{array}$ & $\begin{array}{c}\text { Calculated } \\
\text { flash point }\left[{ }^{0} \mathbf{C}\right]\end{array}$ \\
\hline $10+30+60$ & 0.000113 & 234 & 231 \\
\hline $20+20+60$ & 0.000121 & 230 & 229 \\
\hline $30+20+50$ & 0.000135 & 228 & 226 \\
\hline $50+30+20$ & 0.000171 & 220 & 222 \\
\hline $30+50+20$ & 0.000157 & 225 & 216 \\
\hline $80+10+10$ & 0.000200 & 220 & 224 \\
\hline $20+60+20$ & 0.000150 & 225 & \\
\hline
\end{tabular}

Table 4

MIXTURE CHARACTERISTICS (FLASH POINT)

\begin{tabular}{|c|c|c|c|c|c|c|c|c|c|}
\hline \multicolumn{3}{|c|}{$\begin{array}{l}\text { Imposed limits (min/max) } \\
\text { for the mixture properties }\end{array}$} & \multicolumn{3}{|c|}{$\%$ optimal } & \multicolumn{3}{c|}{ Calculated mixture properties } & $\begin{array}{c}\text { Minimum } \\
\text { unitary cost } \\
{[\text { S/barrel] }}\end{array}$ \\
\hline $\mathbf{v}[\mathrm{cSt}]$ & $\mathrm{Pp}\left[{ }^{\circ} \mathrm{C}\right]$ & $\mathrm{T}\left[{ }^{\circ} \mathrm{C}\right]$ & LO & MO & HO & v [cSt] & Pp [ $\left.{ }^{\circ} \mathbf{C}\right]$ & $\mathrm{T}\left[{ }^{\circ} \mathrm{C}\right]$ & \\
\hline $58 / 62$ & $-6 /-8$ & $226 / 230$ & 24.0 & 22.0 & 54.0 & 60.30 & -7 & 228 & 242.97 \\
\hline $58 / 62$ & $-6 /-8$ & $224 / 228$ & 42.0 & 0.0 & 58.0 & 60.00 & -8 & 226 & 241.62 \\
\hline $50 / 54$ & $-8 /-10$ & $224 / 228$ & 44.6 & 7.3 & 48.1 & 52.40 & -8 & 225 & 240.35 \\
\hline $31 / 35$ & $-6 /-10$ & $215 / 220$ & 61.0 & 22.0 & 17.0 & 34.40 & -8 & 219 & 235.60 \\
\hline $32 / 36$ & $-6 /-10$ & $218 / 222$ & 57.7 & 25.0 & 17.3 & 34.90 & -8 & 220 & 235.97 \\
\hline $28 / 32$ & $-6 /-10$ & $215 / 220$ & 80.0 & 10.0 & 10.0 & 30.15 & -9 & 217 & 233.00 \\
\hline $33 / 37$ & $-6 /-8$ & $218 / 225$ & 39.0 & 47.6 & 13.4 & 35.30 & -6 & 221 & 237.40 \\
\hline
\end{tabular}

Table 5 OPTIMAL MIXING RECIPES

programming algorithm gave the optimal volumetric fractions for each component, as well as the objective function value (the minimal unitary cost) in each case. The results may be seen in table 5 .

It is interesting and also remarkable that we have imposed quite strict limits for viscosity (with a gap of 4 cSt), pour point (gap of $2^{\circ} \mathrm{C}$ ) and flash point (gap of $4-5^{\circ} \mathrm{C}$ ), which make a very good correlation between the expected values and the calculated ones. For instance, imposing values between $58 \mathrm{cSt}$ and $62 \mathrm{CSt}$ for viscosity, $-6^{\circ} \mathrm{C}$ and $8^{\circ} \mathrm{C}$ for pour point, $226^{\circ} \mathrm{C}$ and $230^{\circ} \mathrm{C}$ for flash point gives an optimal mixture having the calculated values of $60.3 \mathrm{cSt}$, $7^{\circ} \mathrm{C}$ and $228^{\circ} \mathrm{C}$, respectively. For this particular oil, the optimal base oil proportions were determined as $24 \%$ vol. (light oil), $22 \%$ vol. (medium oil) and $54 \%$ vol. (heavy oil). The same good results are observed for other rows from table 5.

\section{Conclusions}

The technology used to obtain commercial lubricating oils may be subject for improvements anytime. Due to the process's own complexity, from small changes to radical optimization, these enhancements are more than welcome in order to lower the production costand increase its quality.
This paper presented a software application developed by the authors in MATLAB ${ }^{\circledR}$, which gets the so-called optimal mixing recipes for obtaining lubricating oils from base oils. In our case, the optimal criterion is the production cost minimization. At first, the mathematical model was presented, proving its validity not only in theory but by using laboratory experiments. Next, we presented the software application's functional structure and a short usage guideline. Finally, some optimal recipes for getting mixtures with imposed properties were presented as examples.

The application's good functionality and robustness was proved, this is why we sustain it may be a necessary tool in any laboratory, as well as for the industrial process assistance.

\section{References}

1.TANASESCU, C., Tehnologia uleiurilor. Editura UPG, Ploiesti, 2002. 2.APOSTOL, N. A., Realizarea uleiurilor lubrifiante finite pornind de la uleiuri de baza indigene si aditivi, PhD Thesis, Petroleum - Gas University of Ploiesti, 1988.

3.BOGATU, L., Rev. Chim. (Bucharest), 65, no. 10, 2014, p. 1230. 4.DRAGOMIR, R. E., ROSCA, P., JUGANARU, T., Rev. Chim. (Bucharest), 68, no. 1, 2017, p. 35.

5.BOGATU, L., TANASESCU, C., Optimum Balance between Extreme Pressure and Antiwear Additives from Gear Lubricants, Rev. Chim. (Bucharest), 64, no. 8, 2013, p. 904. 
6.PAWLAK, Z., Tribochemistry of Lubricating Oils, 1 ${ }^{\text {st }}$ Edition, Vol. 45, Elsevier, Amsterdam, 2003, p. 3-8.

7.SPEIGHT, J., EXALL, D. I., Refining Used Lubricating Oils, $1^{\text {st }}$ Edition, CRC Press, Boca Raton, FL, 2014, p. 2-29.

8.PETRE, D., RADULESCU, G., TANASESCU, C., Buletinul UPG Seria Tehnicã, LV, 2, 2003, p. 186.

9.RADULESCU, G. A., Uleiuri lubrifiante. In: Progrese in prelucrarea hidrocarburilor (Suciu, Gh. C). Editura Tehnica, Bucuresti, 1984.

10.RADULESCU, G. A., ILEA, M., Fizico-chimia si tehnologia uleiurilor lubrifiante. Editura Tehnica, Bucuresti, 1982.
11.CURIEVICI, I. Optimizarea în industria chimicã. Editura Didactica si Pedagogica, Bucuresti, 1980.

12. Moler, C., Experiments with MATLAB, Electronic edition, MathWorks, Inc., http://www.mathw orks.com/moler, 2011.

13.RADULESCU, G., Rev. Chim. (Bucharest), 58, no. 2, 2007, p. 239. 14.RADULESCU, G., PARASCHIV, N., KIENLE, Rev. Chim. (Bucharest), 58, no. 3, 2007, pp. 349.

$\overline{\text { Manuscript received: } 26.03 .2019}$ 